\title{
EDUCAÇÃO AMBIENTAL APLICADA AO ENSINO DOS SOLOS: O PROJETO DE EXTENSÃO UNIVERSITÁRIA "EDUCASOLOS" COMO UM MEIO DE CONCIENTIZAÇÃO
}

\author{
Jonathan Fernando Costa Alves ${ }^{1}$ \\ Danilo do Carmo da Rocha ${ }^{2}$ \\ Silvanio de Cássio da Silva ${ }^{3}$ \\ Leda Correia Pedro Miyazaki ${ }^{4}$
}

\begin{abstract}
RESUMO
O solo é um dos recursos de maior importância para a existência dos seres vivos, principalmente por fornecer alimentos essenciais para a manutenção da vida e o equilíbrio dinâmico dos ecossistemas por isso a degradação ambiental pode afetar diretamente e indiretamente o recurso natural do solo $e$ consequentemente provocar grande perda de solo fértil. Neste sentido deve-se investir na conscientização ambiental aliada a prática de preservação e conservação do solo, pois no Brasil ainda perde-se muito solo fértil por um uso e um manejo dos solos de forma incorreta. Assim a Faculdade de Ciências Integradas do Pontal, da Universidade Federal de Uberlândia, por meio do Projeto de Extensão Universitário EducaSolos tem como objetivo principal promover a conscientização ambiental de jovens do munícipio de Ituiutaba-Mg, para a conservação $e$ preservação desse recurso natural tão importante. Para isso, foram aplicadas palestras nas escolas públicas e particulares, que abordaram o tema "Formação dos Solos: degradação e conservação". Foram utilizados diversos materiais didáticos, tais como maquetes e experimentos, cujo objetivo foi trabalhar as diferenças existentes entre os solos do município e formas de conservação e preservação. Os resultados se pautaram na organização de um evento intitulado "I Seminário em Comemoração ao Dia Nacional de Conservação dos Solos", no qual foram realizadas diversas atividades que contemplaram ensino (Oficina teórica e prática), pesquisa (minicurso) e extensão (Palestras informativas).
\end{abstract}

PALAVRAS-CHAVE: Solo, Conservação, Preservação.

\footnotetext{
${ }^{1}$ Discente do Curso de Graduação em Geografia, da Faculdade de Ciências Integradas do Pontal, da Universidade Federal de Uberlândia. jonathanfernando10@hotmail.com

${ }^{2}$ Discente do Curso de Graduação em Geografia, da Faculdade de Ciências Integradas do Pontal, da Universidade Federal de Uberlândia. danilodocarmorocha@hotmail.com

${ }^{3}$ Discente do Curso de Graduação em Geografia, da Faculdade de Ciências Integradas do Pontal, da Universidade Federal de Uberlândia. vaninho_udi@hotmail.com

${ }^{4}$ Discente do Curso de Graduação em Geografia, da Faculdade de Ciências Integradas do Pontal, da Universidade Federal de Uberlândia, leda@pontal.ufu.br
} 


\section{ENVIRONMENTAL EDUCATION APPLIED TO EDUCATION OF SOIL: THE UNIVERSITY EXTENSION PROJECT " EDUCASOLOS " AS A MEANS OF CONSCIENTIZATION}

\begin{abstract}
Soil is one of the most important resources for the existence of living beings, mainly by providing essential food for the maintenance of life and the dynamic equilibrium of ecosystems so environmental degradation can affect directly and indirectly the natural resource soil and consequently cause great loss of fertile soil. In this sense one should invest in environmental awareness coupled with the practice of preservation and conservation of soil, as in Brazil still is lost very fertile soil for use and handling of incorrectly soils. Thus the School of Integrated Sciences of the Pontal, the Federal University of Uberlandia, through the EducaSolos University Extension Project aims to promote environmental awareness municipality of youth Ituiutaba-Mg for the conservation and preservation of this natural resource as important. For this, talks were applied in public and private schools, which addressed the theme "Training Soil: degradation and conservation." Various teaching materials were used, such as models and experiments, aimed to work out differences between the county soil and forms of conservation and preservation. The results were based on the organization of an event entitled "I Seminar in Commemoration of the National Day of Soil Conservation", which were carried out various activities that contemplaram education (theoretical and practical workshop), search (short course) and extension (Informative talks).
\end{abstract}

KEYWORDS: Soil, Conservation, Preservation.

\section{EDUCACIÓN AMBIENTAL APLICADA A LA EDUCACIÓN DE SUELO: EL PROYECTO DE EXTENSIÓN UNIVERSITARIA " EDUCASOLOS " COMO MEDIO DE CONCIENTIZACIÓN}

\begin{abstract}
RESUMEN
El suelo es uno de los recursos más importantes para la existencia de los seres vivos, principalmente por el suministro de alimentos esenciales para el mantenimiento de la vida y el equilibrio dinámico de los ecosistemas para la degradación ambiental puede afectar directa e indirectamente a la tierra de los recursos naturales y por lo tanto causa gran pérdida de suelo fértil. En este sentido hay que invertir en la conciencia ambiental, junto con la práctica de la preservación y conservación de los suelos, al igual que en Brasil aún se pierde terreno muy fértil para el uso y manejo de los suelos de forma incorrecta. Así, la Facultad de Ciencias Integradas del Pontal, la Universidad Federal de Uberlandia, a través del Proyecto de Extensión Universitaria EducaSolos tiene como objetivo promover la conciencia ambiental municipal de la juventud ltuiutaba-Mg para la conservación y preservación de este recurso natural tan importante. Para ello, las conversaciones se aplicaron en las escuelas públicas y privadas, que abordaron el tema "La formación del suelo: la degradación y conservación." Se utilizaron diversos materiales didácticos, tales como modelos y experimentos, con el objetivo de resolver las diferencias entre el suelo del condado y formas de conservación y preservación. Los resultados se basan en la organización de un evento titulado "I Seminario en conmemoración del Día Nacional de la Conservación del Suelo", que se llevaron a cabo diversas actividades que comtemplaram educación (taller teórico y práctico), búsqueda (curso corto) y la extensión (Charlas informativas).
\end{abstract}

PALABRAS-CLAVE: Suelo, Conservación, Preservación. 


\section{INTRODUÇÃO}

O solo é um recuso indispensável para a vida humana e o equilíbrio de todos os ecossistemas, e consequentemente é usado pelo homem na produção de alimentos de origem animal e vegetal. Por isso, o uso indevido do solo tem levado muitas vezes a sua degradação, e consequentemente a perda de sua qualidade, além da capacidade de promover suas funções no meio ambiente, como o armazenamento, a filtragem da água, a decomposição de matéria orgânica, o armazenamento de carbono e a biodiversidade.

Nos dias atuais há uma preocupação muito grande com relação ao meio ambiente e de todos os elementos que o compõem, tais como a fauna e a flora. $\mathrm{O}$ homem vem percebendo que há uma grande necessidade de preservar e conservar esse recurso natural, pois o planeta já está dando sinais de problemas ambientais graves, que estão afetando tanto a qualidade do ambiente, quanto a de vida dos seres que habitam o planeta. A complexa questão da escassez de água nas grandes regiões metropolitanas, as quedas bruscas nas produções de alimentos devido à perda de solo fértil, o aumento da temperatura, são indícios desses problemas ambientais.

Todos esses problemas levantados, de alguma forma tem relação direta e indireta com a má utilização do solo, por isso é de extrema importância que a população participe mais ativamente de práticas que permitam preservar e conservar os solos, já que é indispensável para a sobrevivência de todos os seres vivos que habitam no planeta Terra.

Diante disso, enfoca-se a importância de preparar os jovens como formadores de opiniões, que atue em nome da preservação e conscientização ambiental voltada para o recurso natural solo.

Assim, o propósito desse trabalho é relatar as atividades que já foram aplicadas pelos integrantes do Projeto de Extensão Universitária "EducaSolos" da Faculdade de Ciências Integradas do Pontal, da Universidade Federal de Uberlândia, para promover a disseminação de boas práticas que possam contribuir para a preservação e conservação dos solos no município de Ituiutaba/Mg. 


\section{Referencial Teórico}

A educação ambiental ganhou notoriedade com a promulgação da Lei 9.795, de 27 de abril de 1999, que instituiu uma Política Nacional de Educação Ambiental e, por meio dela, foi estabelecida a obrigatoriedade da Educação Ambiental em todos os níveis do ensino formal da educação brasileira. A lei 9.765/99 precisa ser mencionada como um marco importante da história da educação ambiental no Brasil, porque ela resultou de um longo processo de interlocução entre ambientalistas, educadores e governos (BRASIL, 1999).

A principal função do trabalho dentro da escola com o tema Meio Ambiente é construir para a formação de cidadãos conscientes, aptos a decidirem e a atuarem na realidade socioambiental de modo comprometido com a vida, com o bem estar de cada um e da sociedade, local e global. Para isso é necessário que ocorra uma parceria entre escolas (públicas e/ou particulares) e a universidade, com a disseminação de mais informações, práticas/atividades e conceitos/concepções de determinados assuntos. A escola deve trabalhar com seus alunos de forma integrada, envolvendo teoria e práxis, a fim de proporcionar aos seus alunos a capacidade de tomar atitudes, diante de situações problemas, também contribuir na formação de valores, por meio do ensino e a aprendizagem de habilidades e procedimentos. Esse é o grande desafio para a educação. Comportamentos ambientalmente corretos serão aprendidos na prática do dia-a-dia escolar, por meio de gestos de solidariedade, hábitos de higiene pessoal e dos diversos ambientes (PCN, 1999, p.67).

Desse modo, Demo (1993) propõe ensinar de forma mais significativa, sem meramente repassar o saber. O conteúdo deve se motivar do processo emancipatório com base crítico, criativo, atualizado, competente. Não se trata de cercar, temer, controlar a competência de quem aprende, mas dar oportunidade de expandir o conhecimento e a forma de perceber as situações problemas que envolve seu espaço de convivência. Para tal processo de aprendizagem deve conter experiências concretas que levem o estudante à construção gradativa do conhecimento, por meio do fazer cientifico, levando em conta a vinculação da ciência ao seu significado político, social e cultural (CURVELHO E SANTOS,1993 p. 192). 
A principal função do Projeto de Extensão realizados nas escolas é trabalhar o tema Meio Ambiente, tema transversal, por meio do assunto solos, para que seja possível contribuir no processo ensino e aprendizagem e na formação de cidadãos conscientes, aptos a decidirem e a atuarem na realidade socioambiental de modo comprometido com a vida, com o bem-estar de cada um e da sociedade, local e global. Para isso é necessário que, essas informações e conceitos sejam trabalhados nas escolas, em um -primeiro momento, para que em um segundo momento seja trabalhado as atitudes e formas de intervenção, por meio da formação de valores, e a aprendizagem de habilidades e procedimentos. Esse é o grande desafio para a educação, mudar os comportamentos, entre os jovens, que degradam o ambiente, por outro que são considerados ambientalmente corretos, tais como gestos de solidariedade, hábitos de higiene pessoal, hábitos que reduzam 0 consumo exacerbado, que estimulem a reciclagem, o manejo adequado do solo entre outros (PCN, 1999, p.67).

Segundo a EMBRAPA (1999) o solo consiste em conjunto de corpos naturais constituídos por parte sólida, líquida e gasosa, tridimensionais, dinâmicos, formados por materiais minerais e orgânicos, que ocupam a grande parte do manto superficial do planeta Terra. Este contém matéria viva e podem ser vegetados.

A origem da formação dos solos ocorre a partir das ações dos processos intempéricos (físicos, químicos e biológicos), que desagregam e decompõe a rocha matriz.

De acordo com Lepsch (2002), estudos realizados em várias regiões do globo terrestre comprovaram que a existência de diferentes tipos de solos é controlada por cinco fatores, sendo estes: o clima, os organismos vivos, o material de origem (rocha), o relevo e a idade da superfície do terreno (tempo). A interação dinâmica desses fatores propicia a formação do solo e conforme as características do local, no qual envolve tipo de rocha, relevo, macro e micro-organismos, clima, em um determinado tempo, é que se tem a origem de diversos tipos de solos. Como também afirma JENNY (1941), pois o solo é resultante da interação desses cinco fatores ambientais.

Embora pareça simples a dinâmica de formação dos solos a partir dos cinco fatores, o processo é bastante complexo, pois inclui reações e rearranjos do material 
de origem, com eventos que ocorrem em sequência e outros simultaneamente, sendo alguns concorrentes e outros tendo efeitos opostos (FREIRE, 2006).

A partir dessa interação dos fatores de formação (com suas especificidades) e a região tropical, é possível entender a diversidade existente entre os vários tipos de solos, por isso encontramos essa heterogeneidade no Brasil. Essa variedade de solos que ocorre na região tropical permite que se possam exercer todas as atividades que envolvem o solo e produzir, praticamente, todas as culturas, desde que se escolha, dentro desta vasta área, o clima adequado (FREIRE, 2006, p.231).

Atualmente o Sistema Brasileiro de Classificação de solos da Embrapa (SANTOS, et. al., 2006) classifica 13 tipos de solos encontrados no território brasileiros sendo estes: Latossolo, Argissolo, Neossolo, Nitossolo, Cambissolo, Chernossolo, Espodossolo, Gleissolo, Luvissolo, Organossolo, Planossolo, Plintossolo e Vertissolo.

Cada um dos tipos de solos apresenta características diferenciadas, uns mais argilosos, outros mais arenosos, alguns mais profundos, outros mais rasos e assim por diante.

\section{Objetivos}

Assim, a Faculdade de Ciências Integradas do Pontal, da Universidade Federal de Uberlândia, por meio do Projeto Extensão Universitário EducaSolos tem como objetivo principal promover a conscientização ambiental de jovens do munícipio de Ituiutaba-Mg, para a conservação e preservação desse recurso natural tão importante, por meio da utilização de visitas nas escolas e no laboratório PEDOGEO, para ministrar palestras, oficinas, minicursos entre outras atividades.

\section{Metodologia utilizada}

O projeto envolveu uma série de atividades que comtemplaram não só alunos do $1^{\circ}, 2^{\circ}$ e $3^{\circ}$ anos Ensino Médio da escola Municipal Machado de Assis do Município de Ituiutaba/MG, mas também jovens universitários da FACIP/UFU interessados no tema debatido durante o "I Seminário em Comemoração ao Dia Nacional de Conservação do Solo". Dessa forma foram utilizados como procedimentos metodológicos as seguintes etapas: 
1. Preparação e elaboração de material didático-pedagógico para exemplificar técnicas de recuperação de solos e degradação, além de experimentos e amostras de solos com diferentes texturas. Além disso, foi organizado um evento em comemoração ao Dia Nacional de Conservação do Solo, no dia 15 de abril de 2015. Foi confeccionado um folder do I Seminário em Comemoração ao Dia Nacional de Conservação dos Solos, contendo toda a programação do evento, que contou com diversas atividades, entre elas, Palestras, Oficinas e Minicursos;

2. Elaboração de palestra para alunos do ensino médio sobre o tema "Formação de Solos: Conservação e Degradação", para isso foi utilizado um Gibi, ou seja, uma história em quadrinhos, cujas personagens principais foram o Cascão e o Cebolinha, do desenho animado Turma da Mônica, no qual envolveu um diálogo entre as personagens com o tema supracitado;

3. Realização de Palestra para os universitários, no qual enfocou-se como o solo pode ser estudado nas pesquisas científicas, ministrada por uma professora do Curso de Graduação e Pós-Graduação em Geografia;

4. Elaboração de Oficina "Tinta de Solo" para universitários, como um instrumento didático para ser incorporado nas aulas. Nesta oficina utilizou-se experimentos interativos e ilustrativos para que os estudantes e futuros professores pudessem utilizar em suas aulas práticas de solo, com ênfase nos temas: tipos, características, propriedades, importância e degradação do solo;

5. Aplicação de minicurso para identificação de solos por meio da análise granulométrica da EMBRAPA (1997).

\section{Resultados}

Os resultados pautaram-se nas diversas atividades realizadas durante o I Seminário em Comemoração ao Dia Nacional de Conservação dos Solos, realizado tanto na universidade, quanto nas escolas públicas e particulares.

As Palestras, oficinas e minicursos aconteceram nos dias 13, 14, 15, 16 e 17 de abril, sendo o dia 15 de abril a data oficial de comemoração do dia Nacional de Conservação do Solo.

A primeira atividade iniciou-se com as Palestras ministradas pelos monitores do projeto EducaSolos, no qual foi explanada a temática "Formação de Solos: 
Conservação e Degradação". Nesta palestra os monitores escolhiam alguns alunos para fazerem a leitura da história em quadrinhos, com as personagens da Turma da Mônica, que contavam como o solo se forma. Durante a leitura, os alunos do Ensino Médio descobriam cada um dos fatores que contribuem para a formação do solo. $\mathrm{A}$ cada fator de formação do solo apresentado era feito uma pausa na leitura para que os monitores explicassem a importância daquele fator. Somente a título de exemplo, quando foi apresentado o primeiro fator de formação do solo, que no caso foi a Rocha, os monitores explicavam como a rocha contribui para a formação dos solos. Neste caso foi explicado para os alunos que existem três grandes grupos de rochas, sendo estas as sedimentares, as magmáticas e as metamórficas. Cada grupo de rocha apresenta resistências diferenciadas em relação ao "desgaste" ou melhor ao intemperismo químico e físico. Rochas sedimentares quando são intemperizadas desgastam-se mais rapidamente do que rochas ígneas, que são mais resistentes ao processo de intemperismo. Assim, em locais onde encontramos afloramento de rochas sedimentares são mais fáceis de formar solos do que nas ígneas, graças a diferença de resistência. Para ilustrar essa explicação os monitores utilizam amostras de rochas e explicam a diferenças entre elas, como as mesmas se formaram (Figura 01), também fazem testes de permeabilidade colocando água sobre cada uma das rochas e pedem para os alunos observarem em quais rochas a água infiltra mais rápido e quais a água não consegue infiltrar com facilidade.

Figura 1: Palestras (oficinas) realizadas na Escola Municipal Machado de Assis.

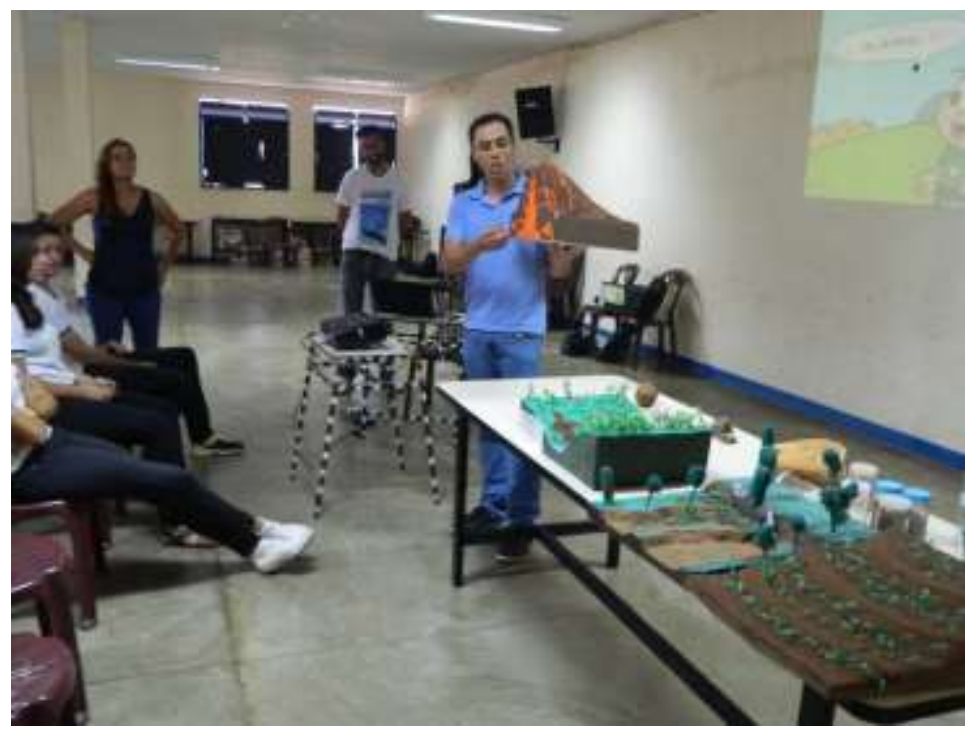

Fonte: Arquivo PEDOGEO, 2015 
As palestras foram interativas, envolvendo a participação dos alunos, dessa forma foi possível apresentar os cinco fatores de formação do solo, sendo esses os tipos de rochas, o clima, o relevo, os macroorganismos e microrganismos e por último o tempo. Todos esses fatores foram explicados a partir da utilização de amostras, experimentos e maquetes didáticas, tudo isso para proporcionar uma melhor compreensão da proposta abordada. Também foram utilizadas diferentes amostras de solos, que variavam tanto na concentração de argila, areia e silte, que são os principais elementos que constituo o solo, quanto na cor.

Os alunos também participaram de alguns experimentos, o primeiro foi sobre a diferença na porosidade em solos, comparando solos do tipo argilosos e arenosos. Assim, foram colocados em dois recipientes identificados com os dois tipos de solos e acrescentado água, assim os alunos puderam observar em qual recipiente a água infiltrava com mais rapidez e qual demorava mais. Com isso, os alunos chegaram à conclusão que os solos argilosos a água levava mais tempo para infiltra e percolar, quando comparados aos solos contendo grande concentração de areia. Diante disso, os monitores explicavam como é importante preservar os solos, pois solos expostos podem ser erodidos com facilidade em eventos chuvosos, principalmente aqueles mais arenosos.

Outro experimento foi realizado, com o objetivo de comprovar que os solos possuem diferentes minerais constituintes, assim foram escolhidas duas amostras de solo e pediu-se para que dois alunos voluntários pegasse um pedaço de imã para realizar o teste. No momento que ambos os alunos colocaram o imã em contato com os recipientes, que continham os solos, e retirando-os logo em seguida, puderam observar que em um dos imãs havia uma grande quantidade de solo fixado e o outro quase não havia solo. Diante disso, os monitores puderam explicar que o solo não é composto apenas de areia, argila, silte, matéria orgânica, água e ar, mas sim que existem diferentes tipos de minerais e que um deles é o Ferro ( $\mathrm{Fe}$ ).

Foram apresentadas também para os alunos maquetes didáticas com o intuito de uma melhor visualização e compreensão dos temas abordados. Por exemplo, utilizou-se uma maquete que demonstrava quais as principais formas de erosão que contribuem para a perda de solos férteis, tais como sulcos, ravinas e voçorocas e como pode-se evitar essas erosões. 
Além das palestras ministradas para os alunos do Ensino Médio, também foi realizada uma palestra para os acadêmicos dos cursos de graduação da FACIP/UFU. A palestra abordou o tema "Conservação dos Solos e Mudanças Climáticas", sendo ministrada por uma professora especialista do assunto. A palestra teve como objetivo apresentar os resultados oriundos da sua pesquisa sobre sequestro de carbono, abordando a metodologia utilizada, bem como os resultados, que permitiu avaliar a má utilização do solo e relacioná-lo com as mudanças climáticas globais, conforme mostra figura 2.

Figura 02: "Palestra Conservação dos Solos e Mudanças Climáticas"

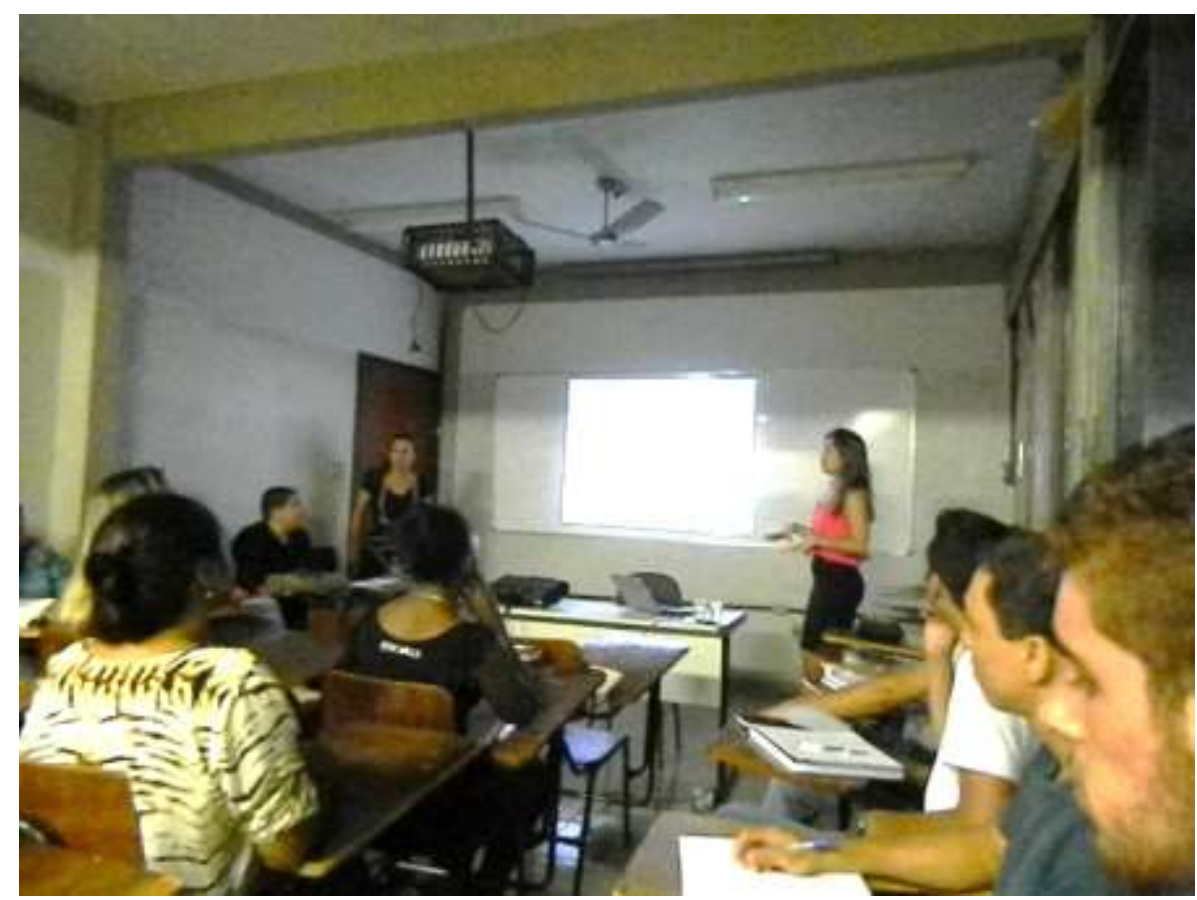

Fonte: Arquivo PEDOGEO, 2015.

No que se refere a aplicação da Oficina "Tinta de Solos", primeiramente foi realizado uma palestra interativa apresentando cada fator de formação do solo, em seguida os monitores apresentaram diferentes amostras de solos para o público alvo, que puderam fazer a texturagem das diversas amostras apresentadas, observando que existem solos mais ásperos (arenosos), solos mais sedosos (siltosos) e mais pegajosos (argilosos), sendo estes os três principais componentes dos solos. Em seguida os alunos observaram que existem diferentes cores de solos, alguns mais vermelhos (Latossolos e Nitossolos), amarelos (Latossolos amarelos), cinza escuro (Gleissolos) entre outros. 
Os alunos foram divididos em grupos, para que a matéria prima pudesse ser distribuída e os outros materiais necessários para se fabricar as tintas de solos. A próxima etapa foi orientá-los na preparação da tinta de solo, utilizando uma receita básica envolvendo cola branca, água e solo destorroado de diferentes cores, conforme figura 3.

Figura 3: Oficina "Tinta de Solos"

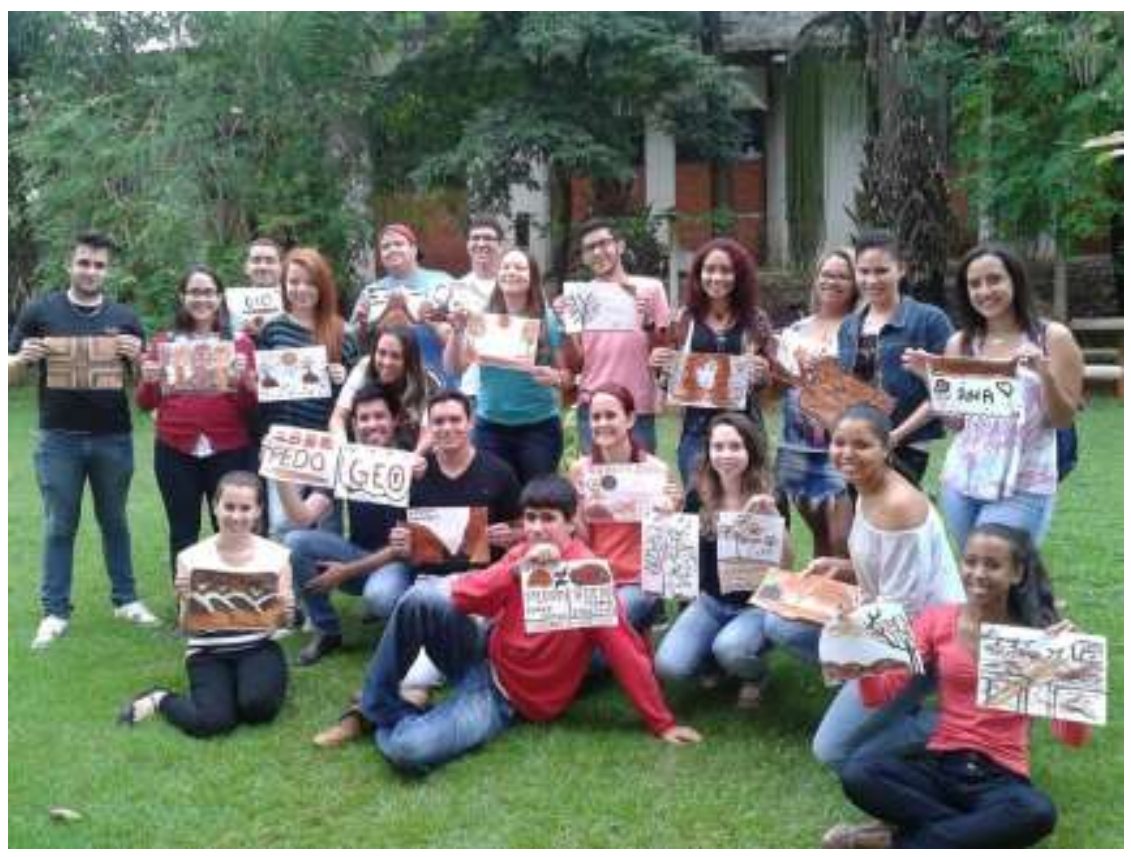

Fonte: Arquivo PEDOGEO, 2015.

A atividade que envolveu o Minicurso "Análise granulométrica" aconteceu em dois encontros, nos dias 16 e 17 de abril, cujo público alvo foram os alunos dos cursos de graduação da FACIP/UFU. Esse minicurso foi ministrado por um dos monitores do projeto. cujo objetivo principal foi instruir uma metodologia de análise granulométrica do solo, conforme metodologia utilizada pela EMBRAPA (1997), para os alunos de graduação pudessem aprender como os solos são identificados $\mathrm{e}$ ressaltar a importância e a utilização desse teste. No primeiro encontro foi transmitida para os alunos toda a metodologia da análise, que consistia desde a obtenção da amostra até a parte final do teste. No segundo encontro, ocorreu à parte prática, assim, os alunos executaram o teste segundo a metodologia apresenta anteriormente, conforme mostra figura 4. 
Figura 4: Minicurso "Análise granulométrica".

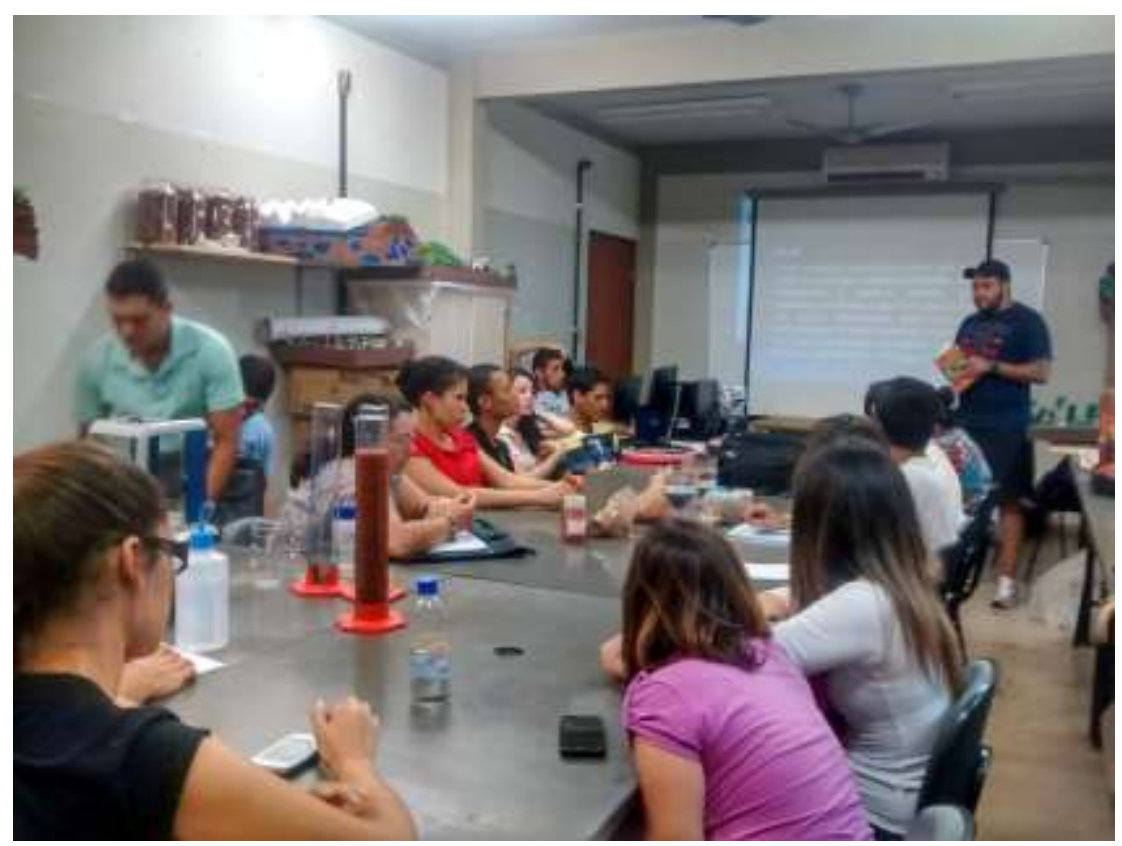

Fonte: Arquivo PEDOGEO, 2015

O I Seminário em Comemoração ao Dia Nacional de Conservação dos Solos realizados, foi uma das atividades do Projeto de Extensão Universitária EducaSolos, que envolveu uma série de palestras voltadas para alunos do Ensino Médio e Universitários, atingindo um público alvo mais jovem, sendo este considerado como um meio de disseminar o conhecimento sobre os solos, que envolveu tanto a sua formação, quanto degradação e conservação.

\section{Conclusão}

O Projeto de Extensão Universitária EducaSolos, é um meio de divulgar o conhecimento sobre o recurso natural Solo, a fim de contribuir para a formação e conscientização dos jovens não apenas do município de Ituiutaba/MG, mas também de grande parte da comunidade acadêmica da FACIP-UFU, já que procura demonstrar à importância dos solos para todos os seres vivos, contemplando principalmente a sociedade.

\section{Agradecimentos}

Agradecimentos especiais a PROEX/PEIC pelo apoio na realização dessas atividades, além de outros colaboradores, como o Curso de Graduação em Geografia e a Direção acadêmica da FACIP/UFU. 


\section{Referências Bibliográficas}

AB'SABER, A.N. - (Re)conceituando Educação Ambiental. Rio de Janeiro: CNPq; MAST, Foulder, 1991. A QUALIDADE da escola aprendente. Disponível em: <http://www.educador.brasilescola.com/trabalho-docente/qualidade-aprendente.htm>. Acesso em: 29 set 2009.

BRANCO, S. M.; CAVINATTO, V. M. Solos a base da vida terrestre.1ed. São Paulo: Moderna. 1999. 79p.

EMPRESA BRASILEIRA DE PESQUISA AGROPECUÁRIA (EMBRAPA). Mapa de reconhecimento dos solos do Triângulo Mineiro. Governo do estado de Minas Gerais, 1980.

GOHN, M. D. G. Educação não formal e o educador social. Atuação no Desenvolvimento de Projetos Sociais. São Paulo: Cortez, 2010, p.19.

GUERRA, A. J. T.; SILVA, A. S.; BOTELHO, R. G. M. Erosão e conservação dos solos. Rio de Janeiro: Bertrand Brasil. 1999. 340p.

LEPSCH, I. F. Formação e conservação dos solos. São Paulo: Prisma, 1977, 178p.

LOUREIRO, C. F. B. Educar, participar e transformar em educação ambiental. Brasília: Rede Brasileira de Educação Ambiental, 2004. 16p.

MUGGLER, C. C; SOBRINHO, F. D. A. P; MACHADO, V. A. Educação em solos: princípios, teorias e métodos. Viçosa. 2006. Disponível em http://www.scielo.br/scielo.php?script=sci_arttext\&pid=S0100-06832006000400014.Aces.Ago.2011

NUNES, J.O. R. Trilhando pelos solos. Presidente Prudente: Capy Set, 2010.

OLIVEIRA, J. B.; JACOMINE, P. K. T.; CAMARGO, M. N. Classes gerais de solos do Brasil: guia auxiliar para seu reconhecimento. 2.ed. Jaboticabal: FUNEP, 1992. 201p.

PEDRO, L. C. A Geografia "Física" no Ensino Fundamental: um relato sobre a importância dos conteúdos e das atividades práticas na formação do aluno. Revista Geografia em Atos (GeoAtos), v. 01, p. 38-57, 2011.

SANTOS, H.G. et. al. Sistema brasileiro de classificação de solos. 2 ed.. Rio de Janeiro: Embrapa Solos, 2006.

TEIXEIRA, Wilson et al. (orgs.). Decifrando a Terra. São Paulo: USP/Oficina de Textos, 2000. $557 \mathrm{p}$.

TRENTIN, R. Mapeamento geomorfológico e caracterização geoambiental da bacia hidrográfica do Rio Itu - oeste do Rio Grande do Sul - Brasil. 2011. 220 p. Tese (Doutorado em Geografia) - Setor de Ciências da Terra, Universidade Federal do Paraná, Curitiba.

UNIVERSIDADE FEDERAL DE VIÇOSA; FUNDAÇÂO CENTRO TECNOLÓGICO DE MINAS GERAIS; UNIVERSIDADE FEDERAL DE LABRAS; FUNDAÇÃO ESTADUAL DO MEIO AMBIENTE. Mapa de solos do Estado de Minas Gerais. Belo Horizonte: Fundação do Meio Ambiente, 2010. Site: http://www.maquinadequadrinhos.com.br/Intro.aspx. Acesso em 14 de fevereiro de 2013. 